\title{
Digital Inclusion and Lifestyle Transformation among the Orang Asli: Sacrificing Culture for Modernity?
}

\author{
Rugayah Hashim ${ }^{1}$, Kartika Sari Idris ${ }^{2}$, Yus Aznita Ustadi ${ }^{2}$, Farah Murni Merican ${ }^{2} \&$ Sharifah F. S. M. Fuzi ${ }^{2}$ \\ ${ }^{1}$ Research Management Institute, Universiti Teknologi MARA, Shah Alam, Selangor, Malaysia \\ ${ }^{2}$ Faculty of Administrative Science \& Policy Studies, Universiti Teknologi MARA, Shah Alam, Selangor, \\ Malaysia \\ Correspondence: Rugayah Hashim, Research Management Institute, Universiti Teknologi MARA, Shah Alam, \\ Selangor, Malaysia. Tel: 60-3-5521-1425. E-mail: hajahgy@gmail.com
}

Received: May 21, 2012 Accepted: June 23, 2012 Online Published: September 20, 2012

doi:10.5539/ass.v8n12p80 URL: http://dx.doi.org/10.5539/ass.v8n12p80

\begin{abstract}
In the Digital Era, being part of the digital society is no longer an option particularly for those living in the urban areas. Caught by the e-wave and the onslaught of sophisticated information and communication technologies (ICT), most urbanites are e-savvy unlike those living in rural locations, particularly the indigenous groups. Is there a need for simple, rural folks to embrace digital literacy and be e-inclusive? Hence, the objective of the study is to assess the level of literacy and computer literacy amongst the indigenous people or natives living in a rural area of Perak, Malaysia. Cross-sectional research design with purposive sampling was employed and the instrument used was a survey form. The findings revealed that $30.8 \%$ of the respondents were illiterate and only $5.2 \%$ who were computer literate thus, substantiating the myth of digital inclusion among the minorities. With the government's transformation plan to have connected citizens through broadband access, the dilemma was the motivation for this research and inherently, substantiated. Although native minorities in Perak, Malaysia formed the sample size for this study, the implications provide justification for policy analysis on socio-technological inclusion among other disadvantaged groups as culture remains strongly ingrained in their every day existence. However, with time, the new generation may revolutionize the outlook of the indigenous group towards modernity and ICT. A change champion together with a positive, political environment would retard the myth and rhetoricism in promoting e-access for social inclusion and citizen development.
\end{abstract}

Keywords: culture, indigenous, digital inclusion, digital divide, e-literacy, Malaysia

\section{Introducation}

Driven by the Digital Era, the Malaysian government's goal of a knowledge or computer literate society by the year 2020 is the foundation of this study. In addition, the Prime Minister's immediate focus or key thrust called the 1Malaysia (One Malaysia) concept of 'People first, Performance now' (Razak 2009) strengthens the need for the conduct of the research. Repeatedly, the government's quest for a knowledge society and ultimately, digital inclusion, has been part of the national plans such as annually tabled budget and prior to that, the Tenth Malaysia Plan (Razak 2010). The successful implementation of country priorities is crucial to all government projects as emphasized by the Deputy Minister of Malaysia's Energy, Water and Communications Ministry where all ongoing programs on closing the digital divide in Malaysia has to be completed by 2010 ( $\mathrm{Li}, 2009)$. With a decade left to Malaysia's goal of achieving a developed nation status, time and citizen participation in embracing and supporting the government's initiatives must be all-encompassing. By closing the digital divide, social inclusion through information and communication (ICT) can be achieved. Alternatively, being digitally inclusive is not an easy process as minorities, particularly the indigenous people or "orang asli" would have to sacrifice some aspects of their culture or lifestyle.

Getting the citizens to be digitaly inclusive is not a new initiative. This has been mentioned since 1997 when Malaysia's Multimedia Super Corridor was launched by then Prime Minister, Datuk Seri Dr. Mahathir Mohamed. A specific project called the e-government flaghsip would ensure inclusion and citizen participation besides automating all government-based processes for efficiency and effectiveness. Regardless, where government-initiated projects are concerned, politics will interfere at the initial implementation stage (Hashim 2008), thus slowing down the success rate. Currently, the irony of the situation is more rhetoric from being 
hyped by polititians - it is in fact a paradox. For example, the vision of broadband access for rural areas is slow in materializing where the 2011 national broadband penetration rate is only $81 \%$ for those living in the metropolitan areas (Bernama, 2011). What then is the penetration rate for the minorities living in rural and remote areas of Malaysia?

Doubtlessly, surfing the internet requires users to be able to read but literacy rate is also low in the rural areas. With the current population of 28.25 million (Department of Statistics Malaysia, 2010), eight percent of Malaysians are illiterate as reflected in the total adult literacy rate of $92 \%$; this is equivalent to the percentage of persons aged 15 and over who can read and write (UNICEF, 2010). This means that approximately 2.3 million citizens are not able to read or write and as such are automatically excluded in the social-economic development (Edzan, 2008). This is an alarming situation and will not brook well for the country's national vision with less than ten years to go. Therefore this study is timely as the assessment on the level of computer literacy among an indigenous group living in a rural area of Malaysia would support the Prime Minister's directive of 'People first' while simultaneously, providing the political leader of the constituent with enough empirical evidence to contain the situation and inherently indicate the act of 'Performance now'.

\subsection{Background of Problem}

As previously mentioned, the objective of this study was to determine computer literacy among a specific indigenous group of Malaysia. Sufficient education and computer usage would denote information and digital inclusion which would thereon lead to e-participation or e-democracy. The choice on the scope of the study was a perfect fit as the as there were limited literature on the topic. Furthermore, this minority group was seldom focused on for political and cultural reasons.

\subsection{The Indigenous Group - the Semais of Perak}

The focus minority group for this study are the indigenous group or locally referred to as 'Orang Asli' Semai living in a small village called Kampung Bukit Terang, which is located in Kampar, Perak. To describe this group, the work of Nicholas (1997) is quoted:

"The Orang Asli are the indigenous minority peoples of Peninsular Malaysia. The name is a Malay term which transliterates as 'original peoples' or 'first peoples.' It is a collective term introduced by anthropologists and administrators for the 18 sub-ethnic groups generally classified for official purposes under Negrito, Senoi and Proto-Malay. They numbered 105,000 in 1997 representing a mere 0.5 per cent of the national population. About 40 per cent of the Orang Asli population - including Semai, Temiar, Che Wong, Jah Hut, Semelai and Semoq Beri - however, live close to, or within forested areas. Here they engage in swiddening (hill rice cultivation) and do some hunting and gathering. These communities also trade in petai, durian, rattan and resins to earn cash incomes".

Furthermore, as shown in Figure 1, the Semaians are only found in parts of Perak and the neighboring state of Pahang. Suffice is to say that the the research project focusing on the Semai tribe comes at an opportune moment. Brief conversations and observation of the village have shown that the Semaians are ready to embrace modenity and technology but the crux of the matter still lies in their interest to be educated and achieve a commendable level of literacy. Sowing their interests and motivating them require the interference of the political leader of that constituent to champion such a noble cause. 


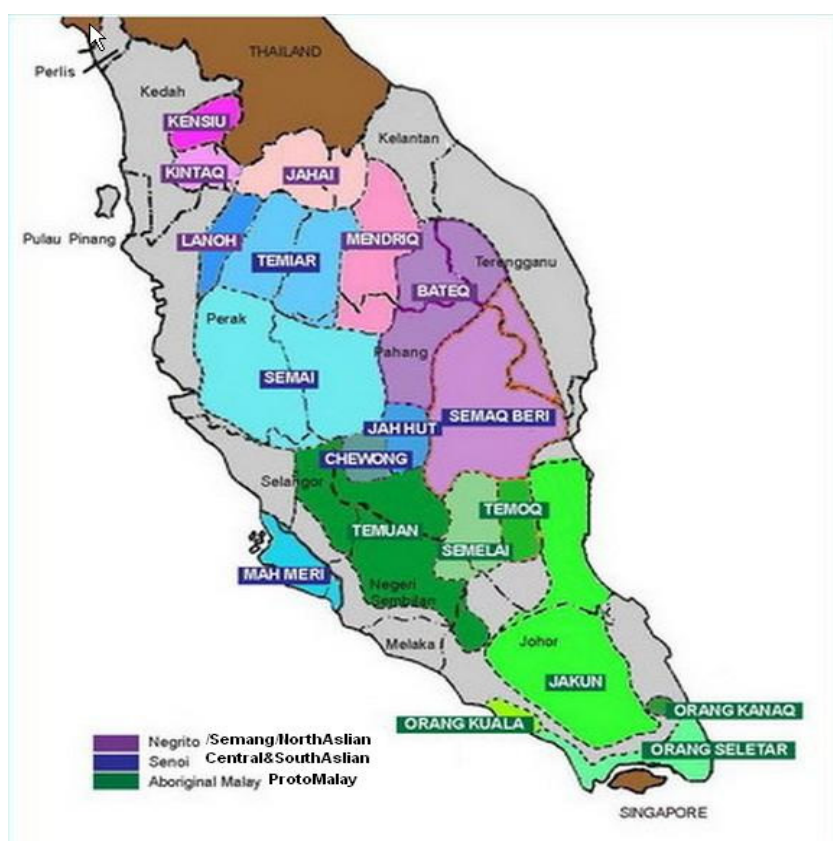

Figure 1. Distribution of natives (orang asli) in west Malaysia (source: orang asli affairs department, 2010)

\subsection{Information and Communication Technology (ICT) in Malaysia}

Information and communication technology strategic roadmap for Malaysia was developed by the the National Information Technology Council (NITC) (MOSTI, 2007) with the objective of transforming Malaysia's economy to a knowledge-based one. Current ICT prominence is focused on e-democracy initiative through e-participation of Malaysians for nation building. In fact, the country's annual national budgets have always emphasized the need for digital literacy and internet usage among the citizens. One of the initiatives is the Universal Service Programme (USP) undertaking amounting to RM600 million that is focused on increasing communications infrastructure in rural areas nationwide (Li, 2009). Also, the recent tabulation of Budget 2011 evidenced the importance of ICT which is the sixth National Key Economic Area (NKEA) from the twelve strategies (Razak, 2010) announced by the Prime Minister. It is hoped that the expansion of the ICT infrastructure across the country will reduce the digital divide and subsequently, benefit all segments of the populace. To re-emphasize, "ICT development is seen as an important strategic driver for positioning Malaysia as competitive K-based economy and global ICT and multimedia hub." (MOSTI, 2007). This is noted, yet realistically, it is not a feasible project because of the the high cost of implementing such a sophisticated infrastructure (Bernama, 2010) and the margin of people who are not computer literate is still significant. Nevertheless, it Malaysia's quest to have an inclusive and computer savvy society, such plans have to be continuously enforced (Rekhari, 2009).

\subsection{What Is Digital Inclusion?}

To put it in simple form, digital inclusion is the positive response to narrowing the digital divide (Jaeger et al, 2012). Digital inclusion encompassess three areas which are access, technology literacy and content services. A society that is digitally inclusive is one that has been embraced by the government's development programs where the community, residents, small business and non-profit organizations are equally provided for. In addition, digitally inclusive community programs (Cushman \& Klecun, 2006) will level the playing field of opportunity with disabilities, at-risk youths, immigrants/refugees and relevant others (Letch \& Carroll, 2008; Helpser, 2008; Cushman \& McLean, 2008).

Under the Malaysian government's four pillars of transformation, a digitally inclusive society falls under the One Malaysia (1Malaysia) motto of "People First, Performance Now", the Economic Transformation Program (ETP) and the 10th Malaysia Plan. Within these three transformation agenda, information and communication technology have been emphasized as the enabler for a connected community (Hashim et al, 2011) and citizen participation through online government initiatives such as e-government and e-participation (Venkatesh, 2012; Yazdanifard et al, 2011; Al-Jaghoub \& Westrup, 2008). 


\section{Method}

The research design employed for the study was a cross-sectional survey with double-stage sampling. For the first stage of the general selection of probability sampling, stratified sampling was deployed, that is, identifying the location of the population. The second stage was convenience sampling where 40 sets of questionnaires were distributed to 40 units of analysis - the Semaians. The minimum respondent number $(n=40)$ was determined on the basis of the total population of 26 families living in the small, rural village of a minority tribe in the state of Perak, Malaysia. An average of $4-5$ members make up a nuclear family, that is, the approximate number of villagers is between 104 to $130(\mathrm{~N}=130)$ people. Thus, at $n=40,30 \%$ of the population was reached. The sample size is considered sufficient as the goal as well as the reporting of the research is for descriptive purposes (Wolfer, 2007; Naing et al. 2006).

It important to note that the completion of the questionnaire was aided by students from the Faculty of Administrative Science and Policy Studies, Universiti Teknologi MARA (UiTM) Shah Alam. The students were at the location because of their project called the Ethnic Outreach. With a bag of gifts to tentalize a respondent, each students approached a Semaian and assisted them in completing the questionnare. This act was extremely helpful as some of the respondents are illiterate. Consequently, this allowed for a highly credible response rate. Data analysis was executed using SPSS version 18 for descriptive statistics and ANOVA.

Also noteworthy is the limitation of this study. As evidenced from the scope, only one indigenous group was focused and generalizability of findings is restricted.

\section{Results}

From the forty questionnaires distributed, 39 (97.5\%) completed ones were collected. The summary for the demograpic profiles of respondents are showcased in Table 1.

Table 1. Description of respondents' profiles

\begin{tabular}{llll}
\hline Profile & & Frequency & Percent (\%) \\
\hline Gender & Male & 12 & 30.8 \\
& Female & 27 & 69.2 \\
Age & Less than 16 years & 11 & 28.2 \\
& 17-25 years & 8 & 20.5 \\
& 26-35 years & 6 & 15.4 \\
Education & More than 36 years & 14 & 35.9 \\
& Primary 6 & 15 & 38.5 \\
& Form 3 (Lower Secondary) & 5 & 12.8 \\
& Form 5 (Middle Secondary) & 5 & 12.8 \\
& Form 6 (Higher Secondary) & 2 & 5.1 \\
& Never went to school & 12 & 30.8 \\
\hline
\end{tabular}

Table 2. Computer ability among respondents

\begin{tabular}{lll}
\hline Item & Scale & Frequency (\%) \\
\hline Use e-mail & Don't know & $30(76.9)$ \\
& Weak & $2(5.1)$ \\
Use word-processing software & Mediocre & $7(17.9)$ \\
& Don't know & $30(76.9)$ \\
& Weak & $3(7.7)$ \\
Able to name computer parts & Mediocre & $5(12.8)$ \\
& Good & $1(2.6)$ \\
& Don't know & $28(71.8)$ \\
& Weak & $3(7.7)$ \\
& Mediocre & $6(15.4)$ \\
& Good & $1(2.6)$ \\
& Very good & $1(2.6)$ \\
\hline
\end{tabular}




\begin{tabular}{lll}
\hline Ability to use the mouse & Don't know & $26(66.7)$ \\
& Weak & $2(5.1)$ \\
& Mediocre & $5(17.9)$ \\
Ability to surf the Net & Good & $3(7.7)$ \\
& Very good & $1(2.6)$ \\
Ability to use search engines & Don't know & $28(71.8)$ \\
& Mediocre & $10(25.6)$ \\
& Good & $1(2.6)$ \\
& Don't know & $28(71.8)$ \\
& Mediocre & $9(23.1)$ \\
\hline
\end{tabular}

\section{Implications and Discussion}

It is important to critically evaluate the implications of the study. First of all, certain limitations have to be taken into account when considering the study and its contributions as some of these limitations can be seen as fruitful avenues for future research under the same area.

This study focused on the existence or non-existance of digital includion of an indigenous segment of society. Clearly, this represents a challenging task at hand regardless of ripple effect of specific interests that the study may have. In this study, the complex phenomenon has been studied from a rather narrow empirical perspective through the selection of a single population or case study. The design naturally brings forth limitations as far as the generalisation of the results of the study is concerned. Thus, the empirical setting, the Semaians from Kampung Bukit Terang, Kampar, Perak should be seen as a kind of pilot context on research pertaining to digital inclusion. On the other hand, this also represents the whole idea of making a case study.

Globalization has resulted in ICT being ubiquitous, but the unparalleled power of the Internet for communication and information is restricted to those with access and capability (Tsatsou, 2011). In achieving set targets and performance criteria for the nation, the government should not lose focus on aspects of culture and ethnocentrism, especially if they involve minorities like the orang asli. The fact that these indigenous people still live deep in the jungles and other remote locations, require the implementation of central plans to be sensitively treaded. The results are indications of social exclusion particularly in education where $30.8 \%$ never went to school and $38.5 \%$ studied up to primary (elementary) school. But at what level did they stop schooling? Consequently, this disadvantaged situation in mirrored in Table 2 where more than $28 \%$ are digitally illiterate. From here, significant transformation needs to take place. In fact, what is required is a change champion, one who is sincerely concerned about the orang asli's well-being and social justice. Nonetheless, it is now clear that digital exclusion has grave implications for Malaysia. Given this information, policy makers should continue to promote digital inclusion by targeting resources and programs for specific dimensions (Yazdanifard et al, 2011; Salman et al, 2012, Wong et al, 2009), for example, ensuring a television set in each home.

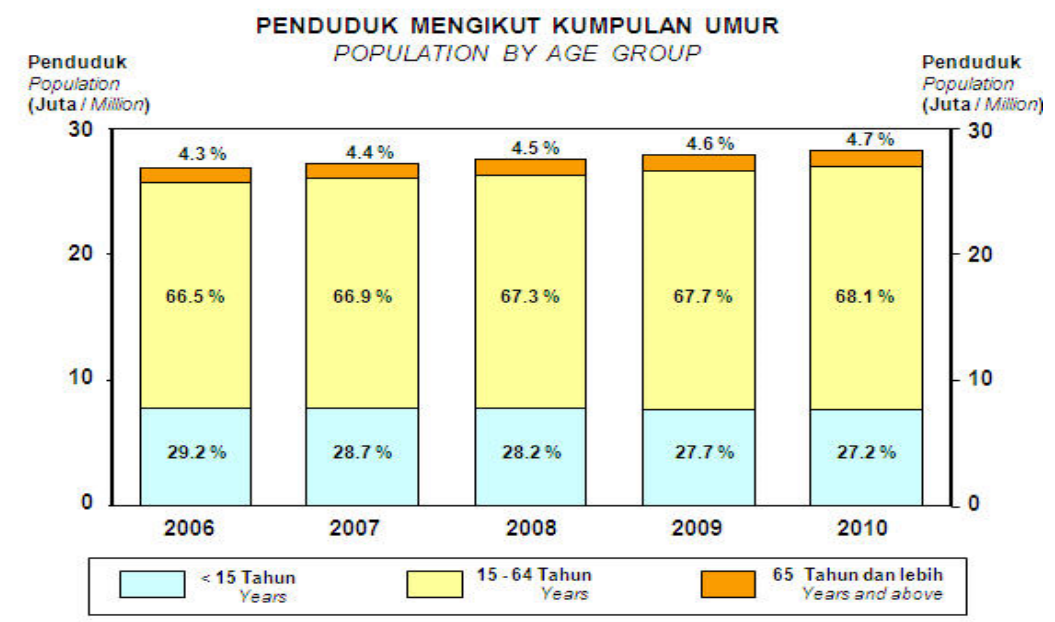

Figure 2. Population of Malaysia by age group (source: department of statistics, Malaysia 2010) 
Table 3. Statistics on education in Malaysia (source: adult literacy - united nations educational, scientific and cultural organization (UNESCO), including the education for all 2000 assessment

\begin{tabular}{ll}
\hline Youth (15-24 years) literacy rate, 2003-2007*, male & $98 \%$ \\
\hline Youth (15-24 years) literacy rate, 2003-2007*, female & 98 \\
Number per 100 population, 2007, phones & 88 \\
Number per 100 population, 2007, Internet users & 56 \\
Primary school enrolment ratio 2003-2008*, gross, male & 101 \\
Primary school enrolment ratio 2003-2008*, gross, female & 100 \\
Primary school enrolment ratio 2003-2008*, net, male & 99 \\
Primary school enrolment ratio 2003-2008*, net, female & 99 \\
Primary school attendance ratio 2003-2008*, net, male & - \\
Primary school attendance ratio 2003-2008*, net, female & - \\
Survival rate to last primary grade (\%) 2003-2008*, admin. data & 99 \\
Survival rate to last primary grade (\%) 2003-2008*, survey data & - \\
Secondary school enrolment ratio 2003-2008*, gross, male & 66 \\
Secondary school enrolment ratio 2003-2008*, gross, female & 72 \\
Secondary school enrolment ratio 2003-2008*, net, male & 66 \\
Secondary school enrolment ratio 2003-2008*, netm female & 72 \\
Secondary school attendance ratio 2003-2008*, net, male & -
\end{tabular}

\section{Conclusion}

The conclusion as well as the limitations of this study also bring forth some fruitful and interesting possible avenues for future research that might be needed in relation to the theme of the study. The most important avenue for future research obviously lies in continuing the elaboration of the elements of the market process. A more thorough understanding of the market from the buyer's perspective could be achieved by considering the connections, hierarchies and interplay of the market process elements more explicitly. However, in this research the decision was made to explicitly separate the elements so that they each could be examined individually. This detachment can be seen to provide a first step towards developing a model for understanding the emerging market from the industrial purchasing perspective. The next step would be to identify the interconnections between the elements and to model the actual market process progress as an interplay of these elements.

From the results, it is deduced that the orang asli Semai are digitally excluded compared to other societies in Malaysia. The findings confirmed the existence of educational divide as well as digital divide. With the former, it is difficult for the government to pursue any ICT-based projects as these natives are socio-economically disadvantaged. However, the government can still reach out to the indigenous people as Malaysia's land area is small $\left(328,657 \mathrm{~km}^{2}\right)$ compared to the United States $\left(9,158,960 \mathrm{~km}^{2}\right)$ and Australia $\left(7,682,300 \mathrm{~km}^{2}\right)$ (Wilson et al, 2003). Socio-economic inclusion is possible with time, training and consistent enforcement (Shaffril et al, 2010; Rahim et al, 2011). This is where the concept of "People first, Performance now" should be practiced. By continuously compounding the benefits of education, the mindset of the orang asli can be adapted to accept that times have moved on and that the flora and fauna can no longer sustain their livelihood.

\section{Acknowledgements}

We acknowledge the contribution and support of the following individuals: Dean, Faculty of Administrative Science \& Policy Studies; Assistant Vice Chancelor of the Research Management Institute (RMI), Mustafar Kamal Hamzah, Head of S\&T Research-RMI, Dr. Oskar Hasdinor Hassan, Head of Social Science Research-RMI, Universiti Teknologi MARA; the liason officer from the Department of Orang Asli, Perak; Kampar District Council and the orang asli (native) Chieftain, Tok Batin, for allowing us to administer the questionnaire to the villagers. We would also like to thank the students for helping us with data collection. 


\section{References}

Al-Jaghoub, S., \& Westrup, C. (2008). Reassessing social inclusion and digital divides. Journal of Information, Communication \& Ethics in Society, 7(2-3), 146-158.

Bernama. (2011, December 12). National Broadband Penetration Rate Reaches 81 percent. Bernama Blis. Retrieved April 27, 2012, from http://blis2.bernama.com/getArticle.do?id=96956\&cid=2

Cushman, M., \& Klecun, E. (2006). How (can) nonusers engage with technology: Bringing in the digitally excluded. IFIP International Federation for Information Processing, 208, 347-364. http://dx.doi.org/10.1007/0-387-34588-4_23

Cushman, M., \& McLean, R. (2008). Exclusion, inclusion and changing the face of information systems research. Information Technology \& People, 21(3), 213-221. http://dx.doi.org/10.1108/09593840810895993

Edzan, N. N. (2008). Information literacy development in Malaysia: A review. Libri, 58, 265-280. http://dx.doi.org/10.1515/libr.2008.027

Hashim, R. (2008). Political issues in ICT implementation in local government. Proceeding of the $4^{\text {th }}$ International Conference on e-government. Melbourne, Australia.

Hashim, R., Baharud-din, Z., Idris, K. S., \&Ustadi, Y. A. (2011). Assessing digital literacy among the Semai tribe of Perak, Malaysia. $3^{\mathrm{RD}}$ International conference on Computer Research and Development (ICCRD 2011), Shanghai, PRC, 11-15 March, Volume 1, Article number 5763962, 9-12.

Helsper, E. (2008). Digital inclusion: an analysis of social disadvantage and the information society. October, 16(5), 88. Retrieved from http://eprints.lse.ac.uk/26938/

Jaeger, P. T., Bertot, J. C., Thompson, K. M., Katz, S. M., \& Decoster, E. J. (2012). The intersection of Public Policy and Public Access: Digital Divide, Digital Literacy, Digital Inclusion, and Public Libraries. Public Library Quarterly, 31(1), 1-20. http://dx.doi.org/10.1080/01616846.2012.654728

Letch, N., \& Carroll, J. (2008). Excluded again: Implications of integrated e-government systems for those at the margins. Information Technology \& People, 21(3), 283-299. http://dx.doi.org/10.1108/09593840810896037

Li, J. (2009). Digital Inclusion, Local Government: Malaysia to speed up digital inclusion. Retrieved October 23, 2010, from http://www.futuregov.asia/articles/2009/mar/10/malaysia-speed-digital-inclusion/

MOSTI. (2007). Strategic ICT Roadmap for Malaysia. Retrieved October 22, 2010, from http://www.mosti.gov.my/mosti/images/pdf/National\%20ICT\%20Roadmap\%20for\%20Malaysia.pdf

Naing, L., T. Winn, T., \& Rusli, B. N. (2006) Practical Issues in Calculating the Sample Size for Prevalence Studies. Archives of Orofacial Sciences, 1, 9-14.

Nicholas, C. (1997). The Orang Asli of Peninsular Malaysia. Retrieved October 23, 2010, from http://www.magickriver.net/oa.htm

Rahim, S. A., Pawanteh, L., \& Salman, A. (2011). Digital inclusion: The way forward for equality in a multiethnic society. Innovation Journal, 16(3).

Razak, M. N. A. (2009). The 1Malaysia Concept Part 1. Retrieved October 23, 2010, from http://www.1malaysia.com.my/blog/the-1malaysia-concept-part-1/?format=pdf

Razak, M. N. A. (2010). Tenth Malaysia Plan 2011-2015: Speech by the Prime Minister in the Dewan Rakyat' the New Straits Times. Retrieved October 22, 2010, from http://www.nst.com.my/nst/Ads/Promo/10MP.pdf

Rekhari, S. (2009). Indigenous communities and new media: questions on the global Digital Age. Journal of Information, Communication \& Ethics in society, 7(2-3), 171-181.

Salman, A., \& Rahim, S. A. (2012). From access to gratification: Towards an inclusive digital society. Asian Social Science, 8(5), 5-15. http://dx.doi.org/10.5539/ass.v8n5p5

Shaffril, H. A. M., Samah, B. A., Hassan, M. A., \& D’Silva, J. L. (2010). Socio-economic factors that impinge computer usage in administration works among village leaders in Malaysia. Scientific Research and Essays, 5(23), 3623-3633.

Tsatsou, P. (2011). Digital divides revisited: what is new about divides and their research? Media, Culture \& Society, 33(2), 317-331. http://dx.doi.org/10.1177/0163443710393865

UNICEF. (2010). Malaysia Statistics: Total adult literacy rate (\%), 2003-2008*'. Retrieved October 22, 2010, from http://www.unicef.org/infobycountry/malaysia_statistics.html 
Venkatesh, V., Chan, F. K. Y., \& Thong, J. Y. L. (2012). Designing e-government services: Key service attributes and citizens' preference structures. Journal of Operations Management, 30(1-2), 116-133. http://dx.doi.org/10.1016/j.jom.2011.10.001

Wilson, K. R., Wallin, J. S., \& Reiser, C. (2003). Social stratification and the digital divide. Social Science Computer Review, 21(2), 133-143. http://dx.doi.org/10.1177/0894439303021002001

Wolfer, L. (2007). Real research: Conducting and evaluating research in social sciences. Boston, MA: Pearson.

Wong, Y. C., Law, C. K., John Yat, J. C. F., \& Chi, J. Y. L. (2009). Perpetuating Old Exclusions and Producing New Ones: Digital Exclusion in an Information Society. Journal of Technology in Human Services, 27(1), 57-78. http://dx.doi.org/10.1080/15228830802459135

Yazdanifard, R., Wan Y. W. F., Adam, K. A., \& Sade, A. B. (2011). E government: Bringing government closer to the citizens. Advances in Information Sciences and Service Sciences, 3(10), 340-344. http://dx.doi.org/10.4156/aiss.vol3.issue10.42 